\title{
Weaning Practices in Mothers of Infants age 6 to 12 months visiting Sandeman Provincial Hospital, Quetta
}

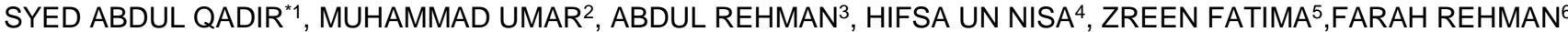 \\ ${ }^{1}$ Medical Officer Paeds, Unit III, Sandeman Provincial Hospital, Quetta, Balochistan \\ 2,3,4,5Final Year MBBS Central Park Medical College Lahore \\ ${ }^{6}$ Assistant Professor of Medical Education Fatima Jinnah Medical University Lahore \\ Correspondence to:Dr. Syed Abdul Qadir, Cell :0092333-7882431, Email : saq.doc@gmail.com
}

\begin{abstract}
Background: Weaning can be described as gradually increasing the amount of foods other than breast 's milk in the infant's diet. Breast feeding for the first four to six months is recommended by the WHO for a full-term healthy child by a healthy mother.

Aim: To find weaning-related factors that contribute, strengthen, and enable mothers of infants under the age of 12 months to obey or not obey guidance for proper infant feeding by World Health Organization's (WHO-2009)

Methods: The current research was a cross-sectional descriptive study. From March 2020 to January 2021, pre design performa was used to collect data from 100 mothers of infants under the age of 12 months who lived in Quetta City and visited at OPD department of Sandeman Provincial Hospital in Quetta. .The multiple rounds of data collection were done. The data was analyzed by SPSS 20 . Statistical test like chi- square test was applied to obtain the required results.

Results: Total 100 babies consist of $41(41 \%)$ male and 59(59\%) femaleenrolled. The mothers in the sample were on average $27.2 \pm 4.2$ years old with the age range of 20-40 years. Results showed that mothers of $6-8$ months' kids $18(45 \%)$ fully aware about the importance of weaning and feed their children with different soft food along with breast feeding which increased at the age of $8-12$ month as $22(73.33 \%)$. Majority of mothers, i.e63\% were housewives. The social status showed lower middle income $34 \%$ and $41 \%$ of research participants belonged to the middle income group.The findings showed that $61 \%$ mothers had inadequate knowledge about proper child feeding and weaning practice compare with other group as $39 \%$ with $p$-value 0.01 .

Conclusion: Mothers should be well informed about the benefits and importance of weaning, as well as the age in which weaning should begin and the different forms of weaning diets available. This target can be met with the assistance of LHWs and LHVs, as well as the use of social media. It is important to stress the importance of continuing to breastfeed after weaning.

Key words: Mothers; Practices; Infants: Weaning.
\end{abstract}

\section{INTRODUCTION}

Weaning is the continued procedure by which a baby gradually becomes used to eat family or adult foods while becoming less reliant on breast milk. The method varies by culture and is often regulated by the child's specific needs. Since healthy babies of weaning age grow and develop at a rapid rate, it's critically to ensure that they get enough of the right kind of food ${ }^{1}$. Weaning causes babies to move around more and become less dependent on their mothers. They begin to expose with germs in the atmosphere and at the same time, the way a baby's body protects itself from germs changes ${ }^{2}$. Even when babies are very young, they still have from protection (immunity) received their mothers during pregnancy. However, this defense wears off after around four to five months, the babies begin to grow their own immunity when they come into contact with germs in the environment ${ }^{3}$. Babies are more likely to contract infectious diseases from the age of 4-5 months due to this change, particularly if they are not breastfed. That is why al food cooked for babies should be processed and fed in a very hygienic way ${ }^{4}$.

The World Health Organization (WHO) recommends that breastfeeding be started as soon as possible, followed by exclusive breastfeeding for the first six months, and then

Received on 13-02-2021

Accepted on 23-05-2021 complementary feeding be introduced in a timely and sufficient amount, frequency, quality, and variety to meet the nutritional needs of the growing baby at the six months of age, with breast feeding continuing up to two years ${ }^{5}$. Weaning or complementary feeding is the process of gradually replacing milk with solid food as the primary source of nutrition. It refers to the administration of any nutrient-rich foods or liquids other than breast milk ${ }^{6}$.

The addition of energy and non-energy containing fluids, non-human milk, and semi-solids or solids to a child's diet is referred to as complementary feeding by the WHO. Weaning is made simpler if the infant has already consumed milk from a source other than the mother's breast $^{7}$

It's a smart idea to give the baby an occasional bottle drink of breast milk from 4 to 7 months (or longer if you want to wean earlier) even if you want to begin breastfeeding, this will help with the weaning process in the future. Although still breastfeeding on demand, natural weaning happens when the baby accepts increasing quantities and forms of complementary feedings ${ }^{8}$.

Full weaning usually happens between the ages of two and four where natural weaning is used. Expected weaning occurs as a mother starts to wean without receiving signals from her baby that he is going to stop breastfeeding. The most critical reasons for weaning are due to returning to work, a new born baby, insufficient 
breast milk or unpleasant feedings, mastitis and poor development of child ${ }^{9}$.

Weaning is influenced by a number of factors, including maternal physiology, nutritional requirements, and developmental status of the infant, such as the biting habit and cultural problems. Due to religious and cultural beliefs, the incidence and extent of breast feeding vary by region. In various cultures around the world, weaning delays, early introduction of alternative feeds, and incorrect weaning from breast milk are all common practices ${ }^{10}$.

For weaning, the texture and consistency of the food is important; specially, soft and yummy foods, such as mashed fruits and vegetables, are preferred. Wheat, gluten, almonds, peas, liver, seafood, shellfish, dairy productsand unpasteurized cheese are most recommended foods for weaning by the National Health Service (NHS) of the United Kingdom ${ }^{11}$.

In Pakistan, the annual child mortality rate estimated about as about 76 per thousand live births. This death ratio indicates that almost 400,000 people would die in their first year of life. According to a survey by the UNICEF, in developing nations, primarily breast-feeding for the first 6 months reduces under-five mortality rates by $13 \% .^{(12)}$.

During the weaning process, mothers typically use a variety of foods such as Khichdi, mashed potatoes, bananas, and eggs, as well as cereal and porridges. Meat consumption is uncommon in Pakistan due to its high cost. Tea, crackers, and rusk are often used during the weaning period in disadvantaged households because they are inexpensive and readily available. ${ }^{(13)}$. Most important purpose of this research was to find out the infant mothers' knowledge of the value of weaning correlated with their educational level, work, and maternal physical and financial health of families. The research also looked at the evidence and how these conditions affect the start of the weaning process at the appropriate age and period, as well as their own health.

\section{MATERIAL AND METHODS}

The conducted study was cross sectional. Data on weaning and infant feeding habits were collected from 100 mothers of infants under the age of 12 months who lived in Quetta City by using a pre-design proforma. The multiple rounds of data collection were done. The data was analyzed by
SPSS 20. Statistical test like Chi- square test was applied to obtain the required results.

Many researchers explore different research variables like age, religion,schooling, profession and monthly family income were included in the earlier literatures. (Qamer et al., 2018) ${ }^{(12)}$, the current investigation was undertaken to ascertain the relationship between literacy level, job load, physical and financial wellbeing of mothers of children. The weaning phase of infants and mothers' literacy levels were used as dependent and independent variables, respectively, in this analysis, whereas physical and financial fitness, level of consciousness, and jobs were used as irrelevant variables..Mothers with infants 6-12 months of age who were agreed for participation were taken as sampleand different languages like English, urdu and Punjabi was used for communication. Those mothers were seriously ill or not willing to participate was excluded. Their personal records of participants and physical appearance were assessed to judge their maternal health.

\section{RESULTS}

Total 100 babies consist of $41(41 \%)$ male and $59(59 \%)$ female enrolled. Results showed that mothers of $6-8$ months' kids 18(455) fully aware about the importance of weaning and feed their children with different soft food along with breast feeding which increased at the age of 812 month as $22(73.33 \%)$.(Table-1)

$18(18 \%)$ of the mothers were illiterate and $14(14 \%)$ of the mothers had primary and middle education and poor information regarding weaning, and 39(39\%) mother had matric and intermediate education had sufficient information as compare with graduate mother $29(29 \%)$ had well educated (Table-2).

The average age of research participants of the study was $27.2 \pm 4.2$ years with age range was $<20$ to 40 years. The basic characteristics included occupation of mothers, social status and awareness about proper child feeding and weaning practice. Majority of mothers, i.e63\% were housewives. Most of the mothers belonged to the middle class income group as $41 \%$. The results showed that $61 \%$ mothers had inadequate knowledge about proper child feeding and weaning practice compare with other group as $39 \%$ with p-value 0.01 (Table-3).

Table 1: Characteristics of the participants $(n=100)$

\begin{tabular}{|l|l|l|l|l|l|}
\hline Age in month & Male & Female & Breast Feeding & No Breast Feeding & Mixed Feeding \\
\hline $4-6$ month & $11(26.6 \%)$ & $19(32.2 \%)$ & $14(46.67 \%)$ & $8(26.67 \%)$ & $8(26.67 \%)$ \\
\hline $6-8$ month & $17(41.5 \%)$ & $23(38.9 \%)$ & $16(40 \%)$ & $6(15 \%)$ & $18(45 \%)$ \\
\hline $8-12$ month & $13(31.7 \%)$ & $17(28.8 \%)$ & $6(20 \%)$ & $2(6.67 \%)$ & $22(73.33 \%)$ \\
\hline Total & $41(41 \%)$ & $59(59 \%)$ & $35(35 \%)$ & $28(28 \%)$ & $37(37 \%)$ \\
\hline
\end{tabular}

Table 2:Literacy level and Awareness about weaning practice

\begin{tabular}{|l|l|l|l|l|l|}
\hline Education's level & Awareness level & Proper time & Early & Delayed & Total Cases \\
\hline Graduation & Well & 24 & 0 & 5 & $29(29 \%)$ \\
\hline $\begin{array}{l}\text { Matric and } \\
\text { Intermediate }\end{array}$ & Sufficient & 3 & 14 & 22 & $39(39 \%)$ \\
\hline Primary and Middle & Poor & 0 & 4 & 10 & $14(14 \%)$ \\
\hline Illiterate & Poor & 0 & 6 & 12 & $18(18 \%)$ \\
\hline
\end{tabular}


Table 3: Late weaning by socio-economic and demographic variables.

\begin{tabular}{|c|c|c|c|c|c|}
\hline \multirow{2}{*}{\multicolumn{2}{|c|}{ Characteristics }} & \multirow{3}{*}{$\begin{array}{l}\text { Frequency } \\
21\end{array}$} & \multicolumn{2}{|c|}{ Late Weaning } & \multirow[t]{2}{*}{ p-value } \\
\hline & & & $\mathbf{N}$ & $\%$ & \\
\hline \multirow{4}{*}{ Maternal Age } & $<20$ & & 6 & 28.57 & \multirow[t]{4}{*}{0.032} \\
\hline & $20-24$ & 35 & 11 & 31.43 & \\
\hline & $25-29$ & 32 & 9 & 28.13 & \\
\hline & $\geq 30$ & 18 & 5 & 27.78 & \\
\hline \multirow{2}{*}{ Maternal occupation } & House wife & 63 & 25 & 39.68 & \multirow[t]{2}{*}{0.042} \\
\hline & Employed & 37 & 8 & 21.62 & \\
\hline \multirow{3}{*}{ Social Status } & Lower Middle Income & 34 & 18 & 52.94 & \multirow[t]{3}{*}{0.03} \\
\hline & Middle Income & 41 & 13 & 31.70 & \\
\hline & Higher Middle Income & 25 & 2 & 8 & \\
\hline \multirow{2}{*}{$\begin{array}{l}\text { Maternal knowledge about proper child feeding } \\
\text { and weaning practice }\end{array}$} & Inadequate & 61 & 15 & 24.59 & \multirow[t]{2}{*}{0.01} \\
\hline & Adequate & 39 & 7 & 17.95 & \\
\hline
\end{tabular}

\section{DISCUSSION}

Breast feeding is free of contamination and full of nutrition which is required in the initial months of life. Some peoples considered breastfeeding a backward way while comparing with bottle feeding, which is believeto be sophisticated. Breastfeeding also prevents breast engorgement. The period from birth to 12 months of age includes the period of breastfeeding and the shift from breast milk to other foods (weaning period), during which children are at greater risk of developing malnutrition and becoming underweight.

The current study was a cross-sectional, quantitative, descriptive study with data collected at single point in time from OPD department of Sandeman Provincial Hospital, Quetta, Balochistan.

It is recommended by different research reports that after 6 months of age, gradual initiation of semisolid and solid food is needed for healthy and proper growth of babies, as only breast milk is insufficient to meet all basic needs and prevent various diseases. (14). The results of current study showed that the mothers of 6-8 month kids $18(45 \%)$ fully aware about the importance of weaning and feed their children with different soft food along with breast feeding which increased at the age of 8-12 month as 22(73.33\%).

Current study showed that the mean age of mothers in the study was $27.2 \pm 4.2$ years with the age range of 20 40 years. Other maternal characteristics included maternal occupation, social status and maternal knowledge about proper child feeding and weaning practice. Majority of mothers, i.e., $63 \%$ were housewives and majority of respondents belonged to the middle income group as $41(41 \%)$. The analysis showed that $61 \%$ mothers had inadequate knowledge about proper child feeding and weaning practice compare with other group as $39 \%$ with $p$ value $0.01^{15}$.

Research conducted by Noor Pur Shahan, total 138 participants enrolled and asked questions regarding their breastfeeding and weaning practices. Research findings showed participant 'sage group 23-26 years. According to the study's findings, $93.4 \%$ of respondents agreed that breastfeeding is good for babies and $94.2 \%$ mothers in this study breast fed their child too ${ }^{16}$.

Duggal et. al (2018) illustrated their results as that 202 children, 103(51\%) were boys. The average age of the participants was 14 and a half months. Among the mothers, $133(66 \%)$ were literate and $121(60 \%)$ were from a low socioeconomic status. $145(72 \%)$ of the infants were exclusively breastfed when they were six months old. Breast-feeding was not given in $51(25 \%)$ of the incidents. In $88(44 \%)$ of the girls, weaning was sufficient ${ }^{17}$..

The results of currents study showed that $18(18 \%)$ of the mothers were illiterate and $14(14 \%)$ of the mothers had primary and middle education and poor information regarding weaning, and 39(39\%) mother had matric and intermediate education had sufficient information as compare with graduate mother $29(29 \%)$ well educated.

According to Umar et al (2013), the most likely causes for this irregularity can be due to illiteracy, work schedules, financial status, maternal and family health $(9 \%$ early weaning initiation and $32 \%$ delayed weaning cases) ${ }^{18-19}$. Another study conducted by Hopkins et. al (2017) reported that some kids were not being weaned till 7 months because their mothers do not understand importance of weaning. Most mothers thought that breast milk sufficient for their kids ${ }^{20}$.

The study conducted by Mohammed et. al (2012) also, all the mothers knew that breastfeeding is the best nutritional source for baby. Results of another study showed that about $79 \%$ of the participants knew that breast milk protects child from diseases ${ }^{21}$.

Safaa et al (2012).revealed the study which showed $42.6 \%$ mothers did not know the suitable age to start weaning. Nearly half $(50.2 \%)$ of the mothers reported that baby must be weaned completely from breast milk at the age of 2 years, these findings support the results of current study $^{22}$.

\section{CONCLUSION}

Mothers must be aware about the importance and effectiveness of weaning, suitable weaning diets and age for beginning. This task can be achieved by the help of social media and LHVs. It is important to stress the importance of continuing to breastfeed after weaning.

Various weaning techniques were used, and mothers found a number of obstacles to following proper breastfeeding procedures. The results emphasise the importance of mothers developing personal expertise in the preparation of nutritionally healthy diets.

\section{REFERENCES}

1. Humphrey LT. Weaning behaviour in human evolution. InSeminars in cell \& developmental biology 2010 Jun 1 (Vol. 21, No. 4, pp. 453-461). Academic Press. 
2. World Health Organization. Weaning: from breast milk to family food, a guide for health and community workers. World Health Organization; 1988.

3. Simon AK, Hollander GA, McMichael A. Evolution of the immune system in humans from infancy to old age. Proceedings of the Royal Society B: Biological Sciences. 2015 Dec 22;282(1821):20143085.

4. Faruque AS, Ahmed AS, Ahmed T, Islam MM, Hossain MI, Roy SK, Alam N, Kabir I, Sack DA. Nutrition: basis for healthy children and mothers in Bangladesh. Journal of health, population, and nutrition. 2008 Sep;26(3):325.

5. Maciel BL, Moraes ML, Soares AM, Cruz IF, De Andrade MI, Junior FS, Costa PN, Abreu CB, Ambikapathi R, Guerrant $\mathrm{RL}$, Caulfield LE. Infant feeding practices and determinant variables for early complementary feeding in the first 8 months of life: results from the Brazilian MAL-ED cohort site. Public health nutrition. 2018 Sep;21(13):2462-70.

6. Motee A, Jeewon R. Importance of exclusive breastfeeding and complementary feeding among infants. Current Research in Nutrition and Food Science Journal. 2014 Aug 28;2(2):56-72.

7. Chaudhry R, Humayun N. Weaning practices and their determinants among mothers of infants. Biomedica. 2007 Jul;23(2):120-4.

8. Lewallen LP, Dick MJ, Flowers J, Powell W, Zickefoose KT, Wall YG, Price ZM. Breastfeeding support and early cessation. Journal of Obstetric, Gynecologic \& Neonatal Nursing. 2006 Mar 1;35(2):166-72.

9. Tarrant M, Fong DY, Wu KM, Lee IL, Wong EM, Sham A, Lam C, Dodgson JE. Breastfeeding and weaning practices among Hong Kong mothers: a prospective study. BMC Pregnancy and Childbirth. 2010 Dec;10(1):1-2.

10. Meedya S, Fahy K, Kable A. Factors that positively influence breastfeeding duration to 6 months: a literature review. Women and birth. 2010 Dec 1;23(4):135-45.

11. Mirza SS, Qamer HM, Shakir HA, Akram RS. Trend Towards Weaning Process of Infants Visiting OPD Pediatrics Unit: An Institutional Based Study. Punjab University Journal of Zoology. 2018;33(2):139-44.

12. Qamer, H.M. and Khan, M.W.A., Liaqat, S., 2018. A cross sectional survey information about weaning process among mothers of infants above 6 months of age in OPD pediatrics at KishwarFazal Teaching Hospital Lahore. Indo Am. J. P. Sci., 05: 3038-3045
13. Salim, S., Kalsoom, S. and Humayun, A., 2016. Weaning practices and perceptions of mothers residing in urban slums of Lahore, Pakistan: A focus group design. Ann. King Edward Med. Coll., 22: 314-320

14. Hopkins, D., Emmett, P., Steer, C., Rogers, I., Noble, S. and Emond, A., 2007. Infants feeding in the second 6 months of the life related to iron status: an observational study. Arch. Dis. Child., 92: 850-854.

15. Ahmed K, Talha M, Khalid Z, Khurshid M, Ishtiaq R. Breastfeeding and weaning: Practices in urban slums of Southern Punjab, Pakistan. Cureus. 2018 Feb;10(2).

16. Ahmed A, Chaudhry AG, Riaz A, Batool A, Farooq H Breastfeeding Knowledge And Practices: An Anthropological Study Of Lactating Mothers Of Noor PurShahan, Islamabad. Science International. 2014 Jan 1;26(1).

17. Duggal MN, Bari A, Iftikhar A. Complementary feeding practices among mothers of children aged six months to two years at Children's hospital Lahore. JPMA. 2020;70(1543).

18. EFSA Panel on Nutrition, Novel Foods and Food Allergens (NDA), Castenmiller J, de Henauw S, Hirsch-Ernst KI, Kearney J, Knutsen HK, Maciuk A, Mangelsdorf I, McArdle HJ, Naska A, Pelaez C. Appropriate age range for introduction of complementary feeding into an infant's diet. EFSA Journal. 2019 Sep;17(9):e05780.

19. Umar AS, Oche MO. Breastfeeding and weaning practices in an urban slum, North Western Nigeria. Int J Trop Dis Health. 2013;3(2):114-25.

20. Hopkins D, Emmett P, Steer C, Rogers I, Noble S, Emond A. Infant feeding in the second 6 months of life related to iron status: an observational study. Archives of disease in childhood. 2017 Oct 1;92(10):850-4.

21. Mohammed ES, Ghazawy ER, Hassan EE. Knowledge, attitude, and practices of breastfeeding and weaning among mothers of children up to 2 years old in a rural area in ElMinia Governorate, Egypt. Journal of family medicine and primary care. $2014 \mathrm{Apr} ; 3(2): 136$.

22. SafaaM, Mohamed AG, Mohamed EM, Khalek EM. Knowledge and practices of working mother about breastfeeding and weaning in Assiut city, Egypt. Life Sci J. 2012;9:803-8

23. Cruz Agudo $\mathrm{Y}$, Jones $\mathrm{AD}$, Berti $\mathrm{PR}$, LarreaMacías $\mathrm{S}$. Breastfeeding, complementary feeding practices and childhood malnutrition in the Bolivien Andes. Arch LatinoamNutr. 2010;60:7-14 